\title{
Autonomia profissional e trabalho assalariado
}

\author{
Professional autonomy and salaried work
}

\section{Jaqueline Lima da SILVA*}

https://orcid.org/o0oo-0001-7784-092X

\section{Rosa Lúcia Prédes TRINDADE**}

https://orcid.org/o0oo-0003-4699-1105

\begin{abstract}
Resumo: Este artigo trata da relação entre autonomia profissional e trabalho assalariado, analisando-a a partir dos aspectos referentes ao controle das condições de trabalho e da técnica profissional. Visa estabelecer uma vinculação entre trabalho assalariado e a perda do controle sobre as condições de trabalho e expor sua consequente interferência no campo da autonomia profissional em virtude da mediação posta pelo mercado de trabalho na sociedade capitalista contemporânea. O resultado dessas discussões fundamenta-se na literatura da sociologia das profissões e na teoria marxista por meio de pesquisa bibliográfica. Conclui que a autonomia profissional por si só não é capaz de empreender um rigoroso controle nas condições de trabalho, pois, o profissional possui o controle da técnica, mas diante da condição de trabalhador assalariado sua autonomia torna-se sempre relativa.
\end{abstract}

Palavras-chave: Autonomia. Condições de Trabalho. Trabalho Assalariado.

Abstract: This article deals with the relationship between professional autonomy and salaried work, analysing the aspects related to the control of working conditions and professional practice. It aims to establish a link between salaried work and the loss of control over working conditions, and to expose its consequent interference in the field of professional autonomy due to the mediation imposed by the labour market in contemporary capitalist society. The results of these discussions are based on literature on the sociology of professions and on Marxist theory through bibliographic research. It concludes that professional autonomy alone cannot fully control working conditions, because, although the professional has the control of their practice, in the face of salaried work, their autonomy always becomes relative.

Keywords: Autonomy; Work conditions; Salaried Work.

Submetido em: 31/7/2019. Aceito em: 30/12/2019.

\footnotetext{
* Assistente Social. Mestre em Serviço Social. Doutoranda PPGSS-UFAL. Assistente Social do Instituto Federal de Alagoas (IFAL, Alagoas, Brasil). Campus Arapiraca, rodovia Estadual AL-110, s/nº, Deputado Nezinho, Arapiraca, CEP.: 57.317-291. E-mail: jaque.lima.as@gmail.com.

** Professora. Doutora em Serviço Social pela Universidade Federal do Rio de Janeiro. Estágio pósdoutoral no Programa de Pós-Graduação em Sociologia e Antropologia da UFRJ. Professora titular da Universidade Federal de Alagoas. (UFAL, Alagoas, Brasil). Campus A. C. Simões, Av. Lourival Melo Mota, s/n ${ }^{\circ}$, Tabuleiro do Martins, Maceió (AL), CEP.: 57072-970. Bolsista PQ-CNPq. E-mail: rosapredes@uol.com.br.
} copiar e redistribuir o material em qualquer suporte ou formato, bem como adaptar, transformar e criar a partir deste material para qualquer fim, mesmo que comercial. O licenciante não pode revogar estes direitos desde que você respeite os termos da licença. 


\title{
INTRODUÇÃO
}

presente artigo aborda algumas análises realizadas na produção científica das áreas de Serviço Social e da Sociologia que refletem acerca da autonomia no trabalho a partir do universo das profissões, nos marcos do capitalismo contemporâneo. A discussão sobre a autonomia profissional contempla temática relevante, porém ainda pouco explorada nas produções científicas do Serviço Social. É recorrente a defesa de que o/a assistente social possui relativa autonomia no exercício da profissão, em geral assentada no entendimento de que a condição de assalariamento interfere diretamente na autonomia profissional, conforme refletem Iamamoto (2015), Raichelis (2018) e Simões (2012). Tal propositura está fundamentada na teoria marxiana para a qual a forma de trabalho assalariado faz com que haja uma perda do controle do trabalhador sobre o seu próprio trabalho. ${ }^{1}$ Por outro lado, a partir do núcleo denominado como Sociologia das Profissões, o debate da autonomia tem se dado por meio de linhas teóricas com bases funcionalistas, pois, conforme Diniz (2001), "[...] foram os sociólogos americanos que delinearam esta área de investigação a partir do final dos anos 30" (DINIZ, 2001, p. 17). A referida autora ressalta ainda que: "Da perspectiva funcionalista, a posição de importância das profissões na sociedade industrial moderna é única. Não é o capitalismo ou a livre empresa que constituem as características mais salientes destas sociedades, mas a emergência dos grupos profissionais" (DINIZ, 2001, p. 18-19).

Temos, portanto, duas linhas de pensamento que se contrapõem acerca da concepção da autonomia profissional. Filiamo-nos à perspectiva teórica marxiana adotada no âmbito do Serviço Social e indagamos: diante das condições postas pelo mercado de trabalho e diante das prerrogativas profissionais garantidas pela regulamentação da profissão, o/a profissional assalariado/a tem autonomia nas condições de trabalho ou no controle da técnica que utiliza? Em que termos se coloca a autonomia relativa de que fala a literatura do Serviço Social? Na tentativa de responder essas questões, buscamos por meio de pesquisa bibliográfica apreender as concepções teóricas desses autores que discutem o referido tema no contexto das profissões, em especial a profissão de Serviço Social, no Brasil.

Apresentaremos, inicialmente, as reflexões dos estudos realizados a partir das contribuições de Diniz (1998; 2001), Antunes (2018) e Felippe (2015), considerando, em especial, as premissas defendidas por Diniz que abordam questões relacionadas à autonomia técnica e ao controle das condições de trabalho. Em seguida, trataremos sobre a autonomia relativa do/a assistente social na sua condição de trabalhador/a assalariado/a, expondo os elementos que consideramos fundantes para estabelecer uma relação intrínseca entre o trabalho assalariado e a perda do controle sobre as condições de trabalho, bem como sua consequente interferência no campo da autonomia técnica em virtude da mediação posta pelo mercado de trabalho.

\section{A AUTONOMIA PROFISSIONAL: CONTROLE DAS CONDIÇÕES DE TRABALHO OU CONTROLE DA TÉCNICA?}

\author{
Para Diniz (2001), autonomia é
}

\begin{abstract}
${ }^{1} \mathrm{Na}$ forma de trabalho assalariado, o produto do trabalho deixa de pertencer ao trabalhador, pois ele entrega ao capitalista a sua capacidade de trabalho em troca de um salário e, a partir desse momento, tudo que o trabalhador produz pertence ao capitalista, uma vez que, ao vender a sua força de trabalho, aquele perde o controle sobre os produtos que foram por ele produzidos e sua força de trabalho se torna uma mercadoria como outra qualquer. Conferir, em especial, os capítulos I e V que tratam sobre a mercadoria e o processo de trabalho e o processo de valorização (MARX, 1996).
\end{abstract}

Argum., Vitória, v. 12, n. 1, p. 174-185, jan./abr. 2020. | ISSN 2176-9575 
[...] a prerrogativa de que gozam os membros de uma profissão de proceder, sem qualquer interferência externa, ao diagnóstico dos problemas no âmbito de sua exclusiva competência técnica, de indicar os procedimentos adequados à sua solução e de se colocarem fora do alcance de eventuais avaliações leigas de seu desempenho profissional. Essa autonomia estaria assentada na natureza complexa do conhecimento adquirido pelo profissional através de um longo período de treinamento devidamente atestado por exames e credenciais (DINIZ, 2001, p. 40).

Essa definição expressa que autonomia está diretamente relacionada ao conhecimento especializado que alguns indivíduos adquirem para exercer determinada profissão. ${ }^{2}$ Contudo, entendemos que toda profissão no modo de produção capitalista está sob dominação do capital e, desse modo, em alguma medida, haverá interferências externas no exercício das profissões. As decisões profissionais não dependerão apenas dos conhecimentos adquiridos e das referências éticas de seus agentes, pois estes se inserem em relações contraditórias de grupos e classes sociais com interesses divergentes.

Dadas as profundas metamorfoses ocorridas no mundo produtivo do capitalismo contemporâneo, o conceito ampliado de classe trabalhadora, em sua nova morfologia, deve incorporar a totalidade dos trabalhadores e trabalhadoras, cada vez mais integrados pelas cadeias produtivas globais e que vendem sua força de trabalho como mercadoria em troca de salário, sendo pagos por capital dinheiro, não importando se as atividades que realizam sejam predominantemente materiais ou imateriais, mais ou menos reguladas (ANTUNES, 2018, p. 31, grifo do autor).

Neste sentido, uma preocupação real apontada por Diniz (2001) refere-se às descobertas de alguns analistas de que há uma redução substantiva da autonomia nas condições de trabalho no capitalismo, acentuando o controle externo às profissões. Tendo em vista que as exigências postas às profissões são mediadas pelo mercado de trabalho, o qual se fundamenta na exploração da força de trabalho por meio do trabalho assalariado, considera-se, ainda, o fato de que:

[...] a história das profissões no Brasil está marcada por reivindicações e negociações com o Estado para o 'fechamento' do mercado de serviços e para a conquista de autonomia corporativa na definição de parâmetros de atuação e fiscalização por meio de associações profissionais (autorregulação) (FELIPPE, 2015, p. 11).

Mesmo nos monopólios profissionais, nos quais se garante certo poder, prestígio, privilégios, reconhecimento legal e definição de espaço no mercado de trabalho, as prerrogativas são marcadas pelos dilemas da exploração do trabalho assalariado e atendem a determinadas funções sociais que se tornam necessárias à legitimação do próprio modo de produção capitalista. Sendo assim, considerar que a condição assalariada interfere na autonomia profissional não significa diminuir ou negligenciar a importância do papel dessas profissões - pelo contrário, entender o seu real significado é poder contribuir com a construção de estratégias que permitam uma atuação consciente no exercício das profissões.

\footnotetext{
${ }^{2}$ No que tange ao conceito de profissão, é importante considerar que "[...] os principais estudiosos concordam em que uma definição 'mínima' deverá fazer referência às profissões como: ocupações nãomanuais que requerem funcionalmente para o seu exercício um alto nível de educação formal usualmente testado em exames e confirmado por algum tipo de credencial. Nas sociedades modernas contemporâneas, 'alto nível de educação formal' significa educação de terceiro grau adquirida normalmente em instituições universitárias, e 'credencial' significa geralmente um diploma [...]" (DINIZ, 2001, p. 18).
} 
Ainda de acordo com Diniz (1998): "As investigações têm mostrado que, mesmo quando o profissional assalariado perde o controle sobre as condições em que trabalha, ele o mantém sobre o processo do seu trabalho, isto é, ele conserva sua autonomia técnica" (DINIZ, 1998, p. 165). A referida autora também argumenta que:

[...] funcionalistas, neoweberianos e neomarxistas parecem concordar em que o conhecimento especializado dos profissionais - sua expertise - garante-lhes, ao contrário do que ocorre com outras categorias ocupacionais - e em particular com os trabalhadores manuais - uma considerável autonomia no trabalho. Para usar uma terminologia mais em voga, os profissionais teriam, individualmente, um extenso controle sobre o processo de trabalho. As divergências situam-se na interpretação do processo pelo qual, nas sociedades modernas contemporâneas, esta autonomia estaria supostamente sendo solapada (DINIZ, 1998, p. 165, grifo nosso).

Pensamos que essa interpretação diverge justamente porque a realidade tem apontado para os reflexos da precarização em todo o mundo do trabalho, desde os países de capitalismo central aos países de capitalismo periférico, pois, de acordo com Antunes (2018), a precarização “[...] trata-se de uma tendência que nasce, conforme Marx demonstrou em O Capital, com a própria criação do trabalho assalariado no capitalismo" (ANTUNES, 2018, p. 59). Nesse contexto:

Não menos importante é dizer ainda que a classe trabalhadora, em sua nova morfologia, participa cada vez mais do processo de valorização do capital e da geração de mais-valor nas cadeias produtivas globais. As formas de intensificação do trabalho, a burla dos direitos, a superexploração, a vivência entre a formalidade e a informalidade, a exigência de metas, a rotinização do trabalho, o despotismo dos chefes, coordenadores e supervisores, os salários degradantes, os trabalhos intermitentes, os assédios, os adoecimentos, padecimentos e mortes decorrentes das condições de trabalho indicam o claro processo de proletarização dos assalariados de serviços que se encontra em expansão no Brasil e em várias partes do mundo, dada a importância das informações no capitalismo financeiro global. Constituem-se, portanto, numa nova parcela que amplia e diversifica a classe trabalhadora (ANTUNES, 2018, p. 64 , grifo do autor).

Diniz (1998) identifica que os profissionais especializados possuem uma vantagem em comparação com os trabalhadores manuais porque podem controlar o processo de trabalho a partir do domínio de determinados conhecimentos e, portanto, estes profissionais teriam uma considerável autonomia no trabalho. Contudo, devemos considerar que, antes de tudo, esse domínio de conhecimentos está submetido à lógica do trabalho assalariado, que na sociedade capitalista tem por função atender às necessidades de acumulação do capital. Assim, sem levar em conta esse processo de precarização ressaltado por Antunes, que atinge toda a classe trabalhadora, parece que tal autonomia é capaz de exercer um maior controle sobre o trabalho apenas ancorada no domínio de habilidades e conhecimentos próprios de cada profissão.

Diante do exposto, entendemos que, seja na relação de trabalhador assalariado, seja na condição de profissional liberal, o fato de determinados trabalhadores com status profissional serem portadores de conhecimento particulares, nem sempre exclusivos, não lhes garante esse extenso controle sobre o processo de trabalho.

Outra questão discutida por Diniz (1998) se refere à tese da proletarização como sinônimo de desprofissionalização, defendendo seus argumentos nos seguintes termos: 
A versão marxista do processo de desprofissionalização é a tese da proletarização dos profissionais em cuja base está a seguinte analogia: o que vem ocorrendo com os profissionais é semelhante ao que ocorreu, primeiro, com os artesãos e, em seguida, com os operários especializados na virada do século. À sujeição ao controle formal do capital ocorrida com a venda da força de trabalho (assalariamento) seguiu-se a sujeição ao controle real quando os trabalhadores foram expropriados tanto do seu saber sobre o processo de trabalho quanto do controle sobre este mesmo processo, e submetidos a uma maciça desqualificação. A analogia tem algum fundamento? (DINIZ, 1998, p. 166, grifo da autora).

Para criticar o que chama de tese de desqualificação do trabalhador especializado, Diniz (1998, p. 167) cita Braverman e se contrapõe às afirmações sobre a degradação do trabalho porque tal questão teria como pano de fundo a tese de que "[...] a divisão técnica do trabalho destrói a autonomia do trabalhador e retira dele o controle sobre o processo de trabalho" (BRAVERMAN, 1977 apud DINIZ, 1998, p. 167). Para ela, a ideia de gerência científica (cf. GOUNET, 1999), como uma criação da produção capitalista que controla o trabalhador e destrói sua perícia e sua habilidade, não se aplicaria às profissões. Tampouco admite que a mecanização possa servir como uma forma de controlar ainda mais e limitar a autonomia profissional. Na visão de Diniz (1998), tal tese teria sido adotada como referência por neomarxistas e teria recebido muitas críticas que negariam qualquer possibilidade de ser considerada válida para o universo das profissões, pois, “[...] em inúmeros casos a tese é simplesmente desconfirmada por detalhados estudos in loco do processo de trabalho" (DINIZ, 1998, p. 169).

Mas, será que não há fundamento nessa analogia? É sustentável afirmar que as profissões estariam blindadas dessas alterações que impactam o mundo do trabalho? Estas reflexões nos levam aos estudos mais recentes realizados por Antunes (2018).

Em pleno século XXI, mais do que nunca, bilhões de homens e mulheres dependem de forma exclusiva do trabalho para sobreviver e encontram, cada vez mais, situações instáveis, precárias, ou vivenciam diretamente o flagelo do desemprego. Isto é, ao mesmo tempo que se amplia o contingente de trabalhadores e trabalhadoras em escala global, há uma redução imensa dos empregos; aqueles que se mantêm empregados presenciam a corrosão dos seus direitos sociais e a erosão de suas conquistas históricas, consequência da lógica destrutiva do capital que, conforme expulsa centenas de milhões de homens e mulheres do mundo produtivo (em sentido amplo), recria, nos mais distantes e longínquos espaços, novas modalidades de trabalho informal, intermitente, precarizado, 'flexível', depauperando ainda mais os níveis de remuneração daqueles que se mantêm trabalhando (ANTUNES, 2018, p. 25).

Portanto, podemos apreender que essa condição de exploração intensificada do trabalho atinge em menor ou maior grau todos os trabalhadores, tendo ou não uma profissão. $O$ avanço tecnológico tanto especializa certas profissões como faz desaparecer determinadas especialidades que passam a ser substituídas pela maquinaria.

Outro ponto levantado por Diniz (1998) refere-se à distinção entre desqualificação do trabalho e desqualificação do trabalhador; ela não identifica que esses dois polos se determinam mutuamente, pois a desqualificação do trabalho gera, consequentemente, a desqualificação do trabalhador, e esse fato foi historicamente demonstrado pelo processo da divisão social do trabalho. Avaliamos que a autora apresenta uma visão restrita ao levar em consideração apenas oportunidades individualizadas postas pelo mercado de trabalho e eventuais ondas de progresso econômico vivenciadas em momentos favoráveis para determinadas profissões, o que pode ser observado no trecho a seguir:

Argum., Vitória, v. 12, n. 1, p. 174-185, jan./abr. 2020. | ISSN 2176-9575 
Uma posição (job) pode ser desqualificada, mas o trabalhador absorvido em outras tarefas especializadas criadas pela mudança de tecnologia. De qualquer maneira, se o interesse está no exame da proletarização da força de trabalho, o importante é o total das oportunidades que o trabalhador tem para exercer suas habilidades, e estas não estão necessariamente determinadas somente ao nível do local de trabalho. Outros fatores importantes são a demanda agregada e o nível de emprego, o crescimento de novos setores dinâmicos na indústria, assim como outras variáveis macroeconômicas (DINIZ, 1998, p. 170-171).

Entendemos que Diniz (1998) atribui aos neomarxistas a ideia de que o controle é o objetivo exclusivo do capital como um fim em si mesmo e não pondera que essas oportunidades para o exercício de habilidades perpassam a condição de assalariamento, ou seja, independente de determinações internas e/ou externas, do uso das tecnologias que requer força de trabalho mais especializada, semiespecializada ou, ainda, não-especializada, não muda o fato de que o trabalho nesta sociedade está subsumido ao capital, ainda que mudanças tecnológicas impactem também de forma positiva na qualificação de determinados trabalhadores.

À esta discussão, acrescentamos a ideia de que, especialmente, para as profissões atuantes na chamada área social, faz-se necessário ressaltar os contraditórios processos de regulação das relações sociais, os quais organizam formas de intervenção social que requisitam o trabalho de diferentes profissões (TRINDADE, 2001). Diante das exigências de controle dos conflitos sociais, demanda-se a racionalização de intervenções sociais - com ações que apoiam o estabelecimento e o controle de determinados comportamentos sociais (baseados em normas sociais) -, para cuja consecução estruturam-se instituições, políticas e serviços de atuação de diferentes profissões.

Sendo assim, as respostas institucionais às demandas sociais se concretizam através de ações das diversas profissões, requisitadas para contribuir com essas respostas, para as quais mobilizam conhecimentos, escolhas éticas, habilidades técnicas. Poder e autonomia profissional são questões necessárias aqui, pois, quando as profissões respondem às requisições definidas pela demanda institucional, acionam seu poder de interpretação da realidade e construção de alternativas aos problemas colocados. Quando o/a profissional exerce o seu poder de análise, de proposição, ele/a também está interferindo na constituição das demandas institucionalizadas, pode estar reconhecendo demandas ainda não explicitadas, para que sejam alvo da ampliação de direitos, alargando-se as demandas legitimadas e institucionalizadas.

Diante do que foi exposto, consideramos que Diniz (1998) não concorda com o entendimento de que o assalariamento favorece a perda de controle e a desqualificação do trabalho. Parece ignorar em larga medida a função exercida pela divisão social do trabalho e centra-se nas aparências propiciadas pela inovação tecnológica e nas oportunidades do mercado. Justifica a qualificação do trabalho a partir do processo de trabalho em si mesmo, sem considerar que há interferências externas e que não basta o profissional buscar por excelentes oportunidades no mercado para garantir sua autonomia no trabalho.

Temos que considerar que a autonomia técnica é limitada ao saber de áreas específicas e, dentro dessas áreas, ainda há subdivisões de especialidades. Também as especialidades profissionais têm passado por modificações significativas; algumas são cada vez mais subcompartimentadas em conhecimentos ainda mais específicos, outras mantêm sua generalidade. As condições de trabalho são determinadas a partir do estabelecimento das relações de trabalho, seja com os empregadores ou diretamente com os compradores, como é o caso dos profissionais liberais. Mesmo diante de limitações impostas à autonomia técnica por parte de gerentes ou administradores, dos setores privado ou público, respectivamente, Diniz (1998) argumenta que "[...] a margem de liberdade e independência no trabalho de que ainda assim gozam os

Argum., Vitória, v. 12, n. 1, p. 174-185, jan./abr. 2020. | ISSN 2176-9575 
profissionais não é de forma alguma trivial, sobretudo se comparada à de outras categorias de empregados" (DINIZ, 1998, p. 174). Mas, conforme bem ressalta Antunes (2018):

Um grupo cada vez mais minoritário estará no topo dos assalariados. Entretanto, a instabilidade poderá levá-lo a ruir face a qualquer oscilação do mercado, com seus tempos, movimentos, espaços e territórios em constante mutação. A esses se somam ainda uma massa de 'empreendedores', uma mescla de burguês-de-sipróprio e proletário-de-si-mesmo. Mas é bom recordar que há várias resistências nos espaços de trabalho e nas lutas sindicais a essas formas de trabalho que procuram ocultar seu assalariamento, por meio do mito do trabalho autônomo (ANTUNES, 2018, p. 34, grifo do autor).

A partir desta premissa, a autonomia seria sempre relativa, em menor ou maior medida, a depender das relações de trabalho que se possa estabelecer com a venda da força de trabalho. Quando a profissão possui um determinado saber e, em determinadas ocasiões, seus agentes podem ocupar uma posição funcional hierarquicamente superior aos demais trabalhadores, isso não elimina a relação de exploração à qual está submetida a classe dos trabalhadores assalariados pela classe capitalista.

Portanto, é preciso deixar claro que sendo autonomia técnica e ética uma prerrogativa e uma característica das profissões, ela se insere no contexto de exploração do trabalho pelo capital, a qual rege toda a relação de trabalho, independente se o profissional é mais ou menos qualificado nos termos do trabalho abstrato. Nesse sentido, nem as qualificações nem as oportunidades de caráter individual se sobrepõem à condição generalizada de assalariamento da sociedade. Não julgamos ser sustentável afirmar que a qualificação do trabalhador, bem como do trabalho, está relacionada às oportunidades do mercado de trabalho, cabendo ao trabalhador aproveitar as boas oportunidades para poder gozar de considerável autonomia.

Tal apreensão distancia-se da noção de autonomia relativa construída no Serviço Social, que permite aos sujeitos profissionais romperem com visões deterministas e/ou voluntaristas para se apropriar da dinâmica contraditória dos espaços institucionais e poderem formular estratégias individuais e coletivas que escapem da reprodução acrítica das requisições do poder institucional (RAICHELIS, 2018, p. 35-36, grifo da autora).

Por isso, sobrepor autonomia técnica e relativizar o controle das condições de trabalho significa desconsiderar o papel exercido pela divisão social do trabalho a partir das sociedades de classes, em especial no capitalismo. Isto porque, em geral, consideramos que não há controle das condições de trabalho pelo trabalhador e que a sua autonomia técnica é sempre relativa, pois a autonomia profissional está sempre subordinada ao controle das condições de trabalho e não há sentido em separar o controle das condições de trabalho do controle da técnica.

\section{A AUTONOMIA RELATIVA DO/A ASSISTENTE SOCIAL NA CONDIÇÃO DE TRABALHADOR ASSALARIADO}

Continuamos nossa abordagem, agora salientando alguns aspectos acerca da autonomia profissional no Serviço Social. Conforme salienta Simões (2012), no debate sobre a autonomia profissional no Serviço Social é consenso entre os autores da perspectiva histórico-crítica considerar que esta autonomia do/a assistente social se constitui de forma sempre relativa, pois “[...] seu exercício profissional não se concretiza como liberal em função da sua condição de trabalhador assalariado" (SIMÕES, 2012, p. 76). Tal entendimento se fundamenta especialmente nas formulações expressas por Iamamoto (2015) de que: 
Sendo o Serviço Social regulamentado como uma profissão liberal e dispondo o assistente social de relativa autonomia na condução do exercício profissional, tornam-se necessários estatutos legais e éticos que regulamentem socialmente a profissão. Entretanto, essa autonomia é tensionada pela compra e venda dessa força de trabalho especializada a diferentes empregadores: o Estado (e suas distintas esferas de poder), o empresariado, as organizações de trabalhadores e de outros segmentos organizados da sociedade civil. O significado social do trabalho profissional do assistente social depende das relações que estabelece com os sujeitos sociais que o contratam, os quais personificam funções diferenciadas na sociedade (IAMAMOTO, 2015, p. 214-215, grifo da autora).

Desse modo, ser um trabalhador assalariado exerce interferência direta tanto na autonomia profissional quanto nas condições de trabalho, pois, aos empregadores, caberá todo um controle das condições de trabalho, ainda que "[...] a condição de assalariado do Assistente Social tensiona a sua autonomia, mas não inviabiliza o direito de exercer sua atividade profissional através da sua expertise ou conhecimento especializado" (SIMÕES, 2012, pp. 23-24). Afinal, as regulamentações da profissão têm a função de resguardar sua autonomia técnica. Mas, por outro lado, "[...] o que pode inviabilizar esta autonomia ou torná-la bastante reduzida é a precarização da formação profissional e do trabalho do Assistente Social" (SIMÕES, 2012, p. 24). Portanto, o reconhecimento de que as mudanças impostas pelo capital ao trabalho trazem consequências para a atuação das profissões orientam essa análise.

Vale ainda ressaltar que as prerrogativas profissionais são exigidas sob determinadas condições em que se organiza a divisão sociotécnica do trabalho e também as contradições que a permeiam: as condições concretas das políticas sociais, a política econômica, a organização dos trabalhadores e a luta por direitos, a destinação do fundo público, a cultura institucional, as condições de assalariamento no trabalho nos serviços, dentre outros. Neste sentido, concordamos com a afirmação de Iamamoto (2015) de que:

[...] essas relações interferem decisivamente no exercício profissional, que supõe a mediação do mercado de trabalho por tratar-se de uma atividade assalariada de caráter profissional. Ela implica compra e venda da força de trabalho e a presença do equivalente geral - o dinheiro -, que expressa o valor de troca dessa força de trabalho, corporificado no salário, atestando estar essa atividade profissional inserida no reino do valor na sociedade capitalista. Assim, a condição de trabalhador assalariado, regulada por um contrato de trabalho, impregna o trabalho profissional de dilemas da alienação e de determinações sociais que afetam a coletividade dos trabalhadores, ainda que se expressem de modo particular no âmbito desse trabalho qualificado e complexo (IAMAMOTO, 2015, p. 215, grifo da autora).

Assim, ainda que estejam presentes no cotidiano profissional os compromissos ético-políticos, mediante adesão dos/as agentes profissionais aos princípios éticos, estão em jogo relações sociais contraditórias que se reproduzem numa sociedade de classes com interesses antagônicos na luta incessante entre capital e trabalho.

A condição assalariada - seja como funcionário público ou assalariado de empregadores privados, empresariais ou não - envolve, necessariamente, a incorporação de parâmetros institucionais e trabalhistas que regulam as relações de trabalho, consubstanciadas no contrato de trabalho, que estabelecem as condições em que esse trabalho se realizem: intensidade, jornada, salário, controle do trabalho, índices de produtividade e metas a serem cumpridas. Os empregadores definem ainda a particularização de funções e atribuições consoante a normas que regulam o trabalho coletivo. Oferecem, ainda, o 
background de recursos materiais, financeiros, humanos e técnicos indispensáveis à objetivação do trabalho e recortam as expressões da questão social que podem se tornar matéria da atividade profissional (IAMAMOTO, 2015, p. 218, grifo da autora).

Por tudo isso, mesmo considerando o status de profissão, que possui um conhecimento especializado, há que se levar em conta as interferências colocadas pela compra e venda da força de trabalho, pois o mercado tem suas próprias regulações e atinge de alguma maneira a autonomia das profissões, ainda que em menor ou maior medida. Destarte, vê-se que as condições de trabalho definem a base para as condições éticas e técnicas, pois, além das relações de trabalho, elas também colocam as condições para o acesso aos insumos, a estrutura para atendimento da população, as condições para a garantia do sigilo profissional, enfim, para o exercício profissional de forma geral.

Nesse contexto, considerando em particular o Serviço Social, na proposição defendida por Iamamoto (2015), afirma-se que, diante da inserção na divisão social do trabalho e da condição assalariada, a autonomia profissional é sempre relativa, uma vez que:

O dilema condensado na inter-relação entre projeto profissional e estatuto assalariado significa, por um lado, a afirmação da relativa autonomia do assistente social na condução de suas ações profissionais, socialmente legitimada pela formação acadêmica de nível universitário e pelo aparato legal e organizativo que regulam o exercício de uma "profissão liberal" na sociedade (expresso na legislação pertinente e nos Conselhos Profissionais). Aquela autonomia é condicionada pelas lutas hegemônicas presentes na sociedade que alargam ou retraem as bases sociais que sustentam a direção social projetada pelo assistente social ao seu exercício, permeada por interesses de classes e grupos sociais, que incidem nas condições que circunscrevem o trabalho voltado ao atendimento de necessidades de segmentos majoritários das classes trabalhadoras (IAMAMOTO, 2015, p. 415).

Portanto, a condição assalariada interfere diretamente no exercício da profissão. Conforme expressa Raichelis (2018): "Em nossa visão, não cabe atribuir à natureza abstrata e complexa do corpo de connhecimentos produzidos por uma profissão o elemento determinante e garantidor de sua autonomia (para nós sempre relativa) e autocontrole institucional profissional" (RAICHELIS, 2018, p. 36). É preciso considerar que a mercantilização é uma condição que perpassa toda e qualquer profissão na sociedade capitalista, das mais clássicas às mais contemporâneas. Tais profissões são marcadas pelo assalariamento.

Segundo Felippe (2015), a condição assalariada já vem sendo alvo de debates no interior da sociologia das profissões, "[...], o assalariamento, o controle hierárquico e a definição externa das condições de trabalho são elementos presentes desde o surgimento de determinadas profissões" (FELIPPE, 2015, p. 18). O referido autor considera que para a maioria das profissões, das quais muitas já nasceram assalariadas, o caráter relativo da autonomia será sempre relativo, mas isso não interferiria no controle da técnica.

Por essa razão, não se trata de avaliar em que medida se faz ou não um melhor aproveitamento das oportunidades do mercado; é preciso reconhecer quais são as interferências que resultam dessa condição de assalariamento no campo dessas profissões. Em se tratando do Serviço Social, e se pudermos considerar as demais profissões assalariadas, temos clareza que:

[...] durante o período em que trabalha, sua atividade é socialmente apropriada por outro: o sujeito que trabalha não tem o poder de livremente estabelecer suas prioridades, seu modo de operar, acessar todos os recursos necessários, 
direcionar o trabalho exclusivamente segundo suas intenções, o que é comumente denunciado como o 'peso do poder institucional'. Simultaneamente, o assistente social tem como base social de sustentação de sua relativa autonomia - e com ela a possibilidade de redirecionar o seu trabalho para rumos sociais distintos daqueles operados pelos seus empregadores - o próprio caráter contraditório das relações sociais (IAMAMOTO, 2015, p. 422).

Por isso é tão importante desvendar o papel das classes sociais e as possibilidades das profissões no contexto da divisão social do trabalho, visto que as atividades profissionais não estão acima da relação de classe, as profissões não se constituem em si mesmas, elas são permeadas por relações sociais. Assim,

[...] verifica-se, pois, uma tensão entre o trabalho controlado e submetido ao poder do empregador, as demandas dos sujeitos de direitos e a relativa autonomia do profissional para perfilar o seu trabalho. Assim, o trabalho do assistente social encontra-se sujeito a um conjunto de determinantes históricos, que fogem ao seu controle e impõe limites, socialmente objetivos, à consecução de um projeto profissional coletivo no cotidiano do mercado de trabalho (IAMAMOTO, 2015, p. 424, grifo da autora).

É com essa visão de profissão, inserida em relações de trabalho capitalistas, marcada por processos como os de alienação do trabalho, que conseguimos entender as relações contraditórias pertinentes à realidade profissional no cotidiano das instituições que empregam assistentes sociais. Por outro lado, não se deve abrir mão de uma formação específica e qualificada, da aquisição de uma autoridade e de uma responsabilidade profissional, ainda que haja a mediação do assalariamento. A capacidade e a necessidade de escolhas devem ser fundadas em análises científicas sobre a realidade e assumidas com responsabilidade ética, através de ações reguladas. Nessa combinação contraditória entre trabalho e profissão, é possível elucidar o significado social desta profissão e não mascarar ainda mais sua condição de trabalhador assalariado, sem abrir mão das possiblidades construídas no âmbito dos limites próprios ao exercício profissional na sociedade capitalista. Vimos nessas discussões que há lacunas que precisam ser preenchidas por pesquisas que se proponham a analisar a realidade social em sua totalidade e que abordem todos os aspectos de nossa complexa condição de trabalhadores assalariados.

\section{CONSIDERAÇÕES FINAIS}

É possível entender que as profissões garantem aos seus membros autonomia devido ao conhecimento especializado que possuem - sua expertise -, o que lhes confere determinado poder no exercício de sua profissão. Mas também precisamos considerar que essa autonomia profissional se coloca nas inúmeras contradições presentes num mercado de trabalho profissional que está sob os ditames do capital, pois, numa sociedade regida pela lógica do modo de produção capitalista, o trabalho é perpassado pelas amarras impostas pelo assalariamento. A partir desse entendimento, reafirmamos que as análises acerca das profissões na sociedade capitalista exigem a imprescindível articulação com sua condição de assalariamento, o que nem sempre é pautado pelos autores que discutem a questão, como pudemos perceber nesse texto. Muitas vezes se tem uma abordagem sobre o universo das profissões como se a autonomia dos profissionais fosse, por si só, capaz de empreender um rigoroso controle nas condições de trabalho.

Diante desse debate, entendemos que a produção científica do Serviço Social oferece uma importante contribuição ao problematizar sobre a autonomia relativa do/a assistente social frente à condição de trabalho assalariado, pois suas formulações trazem para a discussão os fundamentos da relação capital versus trabalho, expressando a primazia da teoria do valor trabalho.

Argum., Vitória, v. 12, n. 1, p. 174-185, jan./abr. 2020. | ISSN 2176-9575 
Percebemos neste debate que autores da sociologia das profissões, ao contrário, apresentam uma tendência ao superdimensionamento da função social das profissões e desconsideram, em larga medida, que há interferências externas devido às exigências postas pela mediação do mercado de trabalho, fundamentado na exploração da força de trabalho. Nesse sentido, visualizamos que o centro das preocupações está na garantia dos monopólios profissionais, dando prioridade nas suas formulações para estratégias que possam resguardar um lugar no mercado de trabalho, de modo que se torna desnecessário discutir a teoria do valor trabalho porque o mercado ganha destaque nessas discussões.

Por fim, reafirmamos que as profissões não têm um fim em si mesmas, sendo permeadas por relações sociais e tensionadas pela compra e venda da força de trabalho. Nessas condições, em geral, o profissional possui o controle da técnica, mas não o controle das condições de trabalho, já que sua autonomia diante do assalariamento se torna sempre relativa. Deste modo, concluímos neste breve estudo que, na sociedade regida pelo capital, o trabalho está condicionado a restrições, ainda que no âmbito das profissões liberais altamente regulamentadas. Entendemos que não há condições para o exercício da autonomia absoluta sob a regência da condição assalariada, especialmente na contemporaneidade, tendo em vista que as alterações recentes no mundo do trabalho criam essa nova morfologia do trabalho, conforme as definições expostas anteriormente por Antunes (2018).

\section{REFERÊNCIAS}

ANTUNES, Ricardo. O privilégio da servidão: o novo proletariado de serviços na era digital. São Paulo: Boitempo, 2018.

DINIZ, Marli. Repensando a teoria da proletarização dos profissionais. Revista Tempo Social, São Paulo, v. 10, n. 1, p. 165-184, 1998.

DINIZ, Marli. Os donos do saber: profissões e monopólios profissionais. Rio de Janeiro: Revan, 2001.

FELIPPE, Jonis Manhães Sales. Contribuições da sociologia das profissões para a reflexão sobre a autonomia e os monopólios interventivos do serviço social. Revista Sociedade em Debate, Pelotas, v. 21, n. 1, p. 9-32, 2015.

GOUNET, Thomas. Fordismo e Toyotismo: na civilização do automóvel. São Paulo: Boitempo, 1999.

IAMAMOTO, Marilda Villela. Serviço Social em tempo de capital fetiche: capital financeiro, trabalho e questão social. São Paulo: Cortez, 2015.

MARX, Karl. O Capital: Crítica da Economia Política. Livro Primeiro. São Paulo: Nova Cultural Ltda., 1996.

RAICHELIS, Raquel. Serviço Social: trabalho e profissão na trama do capitalismo contemporâneo. In: RAICHELIS, Raquel; VICENTE, Damares; ALBUQUERQUE, Valéria (Orgs.). A nova morfologia do trabalho no Serviço Social. São Paulo: Cortez, 2018.

SANTOS, Claudia; BACKX, Sheila; GUERRA, Yolanda (orgs.). A dimensão técnico-operativa no Serviço Social: desafios contemporâneos. São Paulo: Cortez, 2017. 
SIMÕES, Nanci Lagioto Hespanhol. Autonomia Profissional X Trabalho Assalariado: exercício profissional do Assistente Social. 2012. 165 f. Dissertação (Mestrado em Serviço Social)-Faculdade de Serviço Social, Universidade Federal de Juiz de Fora, Juiz de Fora, 2012. Disponível em: http://www.ufff.br/ppgservicosocial/files/2012/05/nanci.pdf. Acesso em: 16 jul. 2019.

TRINDADE, Rosa L. P. Desvendando as determinações sócio-históricas do instrumental técnico-operativo do Serviço Social na articulação entre demandas e projetos profissionais. Temporalis, Brasília (DF): Associação Brasileira Ensino e Pesquisa em Serviço Social, n. 4, p. 21-42, 2001.

Jaqueline Lima da SILVA trabalhou na concepção e delineamento do artigo e na redação e revisão final Doutoranda pelo Programa de Pós-Graduação em Serviço Social da Universidade Federal de Alagoas (UFAL). Mestre em Serviço Social pela Universidade Federal de Alagoas. Assistente Social do Instituto Federal de Alagoas. Pesquisadora do Grupo de Pesquisa Mercado de Trabalho do Serviço Social.

Rosa Lúcia Prédes TRINDADE trabalhou na análise e interpretação dos dados e na revisão crítica da redação

Professora titular da Universidade Federal de Alagoas - graduação e pós-Graduação stricto sensu em Serviço Social. Na UFRJ, doutorou-se em Serviço Social (1999) e realizou estágio pós-doutoral no Programa de PósGraduação em Sociologia e Antropologia (2011-2012). Coordena os Grupos de Pesquisa Mercado de Trabalho do Serviço Social e Saúde Mental e Sociedade. Coordena o Programa de Pós-graduação em Serviço Social da UFAL. 